\title{
Ability of Landsat-8 OLI derived texture metrics in estimating aboveground carbon stocks of coppice Oak Forests
}

\author{
A. Safari ${ }^{\text {a }}$ H. Sohrabi ${ }^{\text {a* }}$ \\ a TMU, Natural Resources Faculty, Tehran, Iran - (hsohrabi, amir.safari)@ modares.ac.ir
}

Commission VIII, WG VIII/7

KEY WORDS: Operational Land Imager, Co-occurrence Matrix, Aboveground Carbon Stocks, Stepwise Regression

\begin{abstract}
:
The role of forests as a reservoir for carbon has prompted the need for timely and reliable estimation of aboveground carbon stocks. Since measurement of aboveground carbon stocks of forests is a destructive, costly and time-consuming activity, aerial and satellite remote sensing techniques have gained many attentions in this field. Despite the fact that using aerial data for predicting aboveground carbon stocks has been proved as a highly accurate method, there are challenges related to high acquisition costs, small area coverage, and limited availability of these data. These challenges are more critical for non-commercial forests located in low-income countries. Landsat program provides repetitive acquisition of high-resolution multispectral data, which are freely available. The aim of this study was to assess the potential of multispectral Landsat 8 Operational Land Imager (OLI) derived texture metrics in quantifying aboveground carbon stocks of coppice Oak forests in Zagros Mountains, Iran. We used four different window sizes $(3 \times 3$, $5 \times 5,7 \times 7$, and $9 \times 9)$, and four different offsets $([0,1],[1,1],[1,0]$, and $[1,-1])$ to derive nine texture metrics (angular second moment, contrast, correlation, dissimilar, entropy, homogeneity, inverse difference, mean, and variance) from four bands (blue, green, red, and infrared). Totally, 124 sample plots in two different forests were measured and carbon was calculated using species-specific allometric models. Stepwise regression analysis was applied to estimate biomass from derived metrics. Results showed that, in general, larger size of window for deriving texture metrics resulted models with better fitting parameters. In addition, the correlation of the spectral bands for deriving texture metrics in regression models was ranked as b4>b3>b2>b5. The best offset was [1,-1]. Amongst the different metrics, mean and entropy were entered in most of the regression models. Overall, different models based on derived texture metrics were able to explain about half of the variation in aboveground carbon stocks. These results demonstrated that Landsat 8 derived texture metrics can be applied for mapping aboveground carbon stocks of coppice Oak Forests in large areas.
\end{abstract}

\section{INTRUDUCTION}

With a huge contribution to the global carbon (C) balance, forests play an important role in global carbon cycling (Wen and $\mathrm{He}$, 2016, Chen et al., 2016). Importance of understanding the C cycle contribution to global climate change has highlighted the concerns about surveying of terrestrial $\mathrm{C}$ stocks via methods that are verifiable, specific in time and space, and that cover large areas at acceptable cost (Boudreau et al. 2008; Krankina et al., 2004; Patenaude et al., 2005; Muukkonena and Heiskanenb, 2007).

The traditional approach for estimation forest carbon stocks consists of field data collection and destructive methods. Despite the fact that this approach provides the most accurate results, it is costly, time consuming, labour intensive, and destructive. Furthermore, this approach is not applicable for large area carbon studies. In addition, the spatial heterogeneity of forest $\mathrm{C}$ stocks greatly increase the error of estimation obtained using field data (Dube and Mutanga, 2015a).

To solve such problems, several studies have tried to evaluate accuracy of forest $\mathrm{C}$ estimation by using remotely sensed data (Kwak et al., 2010). The literature demonstrates that RS data is the best practical option to accurately and timely estimate of aboveground forest carbon (AGC) on large scales as well as areas where field surveys remain a challenge, or the area is inaccessible (Zhao et al., 2009; Patenaude, et al., 2004; Kwak et al., 2010; Dube and Mutanga, 2015a).

Different RS data has been evaluated in many researches including RADAR, LiDAR and Optical data. Results demonstrated higher accuracy for carbon and biomass estimations using data provided by active sensors. However, LiDAR data is expensive and SAR data is only available on limited areas. Fortunately, medium-resolution multispectral Landsat 8 images with large swath width of $185-\mathrm{km}$ and frequent repeat cycle is freely available. Because of many advantages of Landsat data, it has been widely used for biomass estimation, but most researches have been advocated to boreal and tropical forests (Behera et al., 2016; Cutler et al., 2012; Fraizer et al., 2014; Neba et al., 2014; Langner et al., 2012) and research on remote-sensing-based biomass estimation for other ecosystems is comparatively scarce (García et al. 2010). Furthermore, methods to select suitable variables and models from RS data for specific studies are still poorly understood (García et al. 2010; Lu et al., 2014).

The Zagros Region covers the Zagros Mountains ranging from northwest to southeast, from the Turkish border to the Persian Gulf. These forests cover an area of 5.5 million hectares (Valipour et al., 2014). The vegetation mostly dominated by deciduous Oak species, and Persian Oak (Quercus brantii Lindl.) is the most frequent species with the largest distribution area. Most trees have coppice form and human activities and fire are two main causes for degradation of these forests. Despite the importance of Zagros forests in $\mathrm{C}$ cycle, very little attention has been paid to the estimation of biomass and carbon of these forests. Most published RS based research in these forest is focused on the estimation of forest coverage and area.

Since Landsat data are freely available, it is the most suitable data for aboveground carbon (AGC) estimation in non-commercial forests (such as Zagros Forests) located in low-income countries. Some literature revealed that texture metrics derived from multispectral data might be a better predictor of biomass than spectral vegetation metrics in some regions (Kelsey and Neff, 2014; Cutler et al., 2012; Dube and Mutanga, 2015b).

Using texture metrics derived from the Advanced Land Observation Satellite, AVNIR-2Sarker, Nichol (2011) estimated AGB with an $R^{2}$ adj value of 0.88 . Eckert (2012) obtained $R^{2}=0.84$ and relative RMSE of $6.8 \%$ for carbon estimates in degraded forest, using WorldView-2 derived texture measures. Cutler et al.

\footnotetext{
* Corresponding author
} 
(2012) achieved r-square of $0.85,81$ and 86 using SAR image texture and Landsat TM for biomass estimates in Brazil, Malaysia and Thailand countries, respectively. Dube and Mutanga (2015b) reported $\mathrm{R}^{2} 0.76$ for estimating AGB in South Africa.

This aim of this research is to explore the potential of Landsat 8 OLI data in AGC estimation in coppice Oak forest of Zagros. Also, different window sizes, texture metrics, offsets, and spectral bands will be examined to find the most correlated data to AGC.

\section{MATERIAL AND METHODS}

\subsection{Study Area}

The study area is located in Zagros forests, in the west of Iran, and occupies part of the Kermanshah province. Two different forests were selected; one of them is Sarfiruz-Abad region with intensive damage by human activities, and the other one is Gahvareh forests with minimum damage (33 $57^{\prime}$ $34^{\circ} 04^{\prime} \mathrm{N} / 47^{\circ} 03^{\prime}-47^{\circ} 17^{\prime} \mathrm{E} \& 34^{\circ} 21^{\prime}-34^{\circ} 24^{\prime} \mathrm{N} / 46^{\circ} 16^{\prime}-46^{\circ} 23^{\prime} \quad$ E) (figure 1). Both forests are dominated by Quercus brantii Lindl.

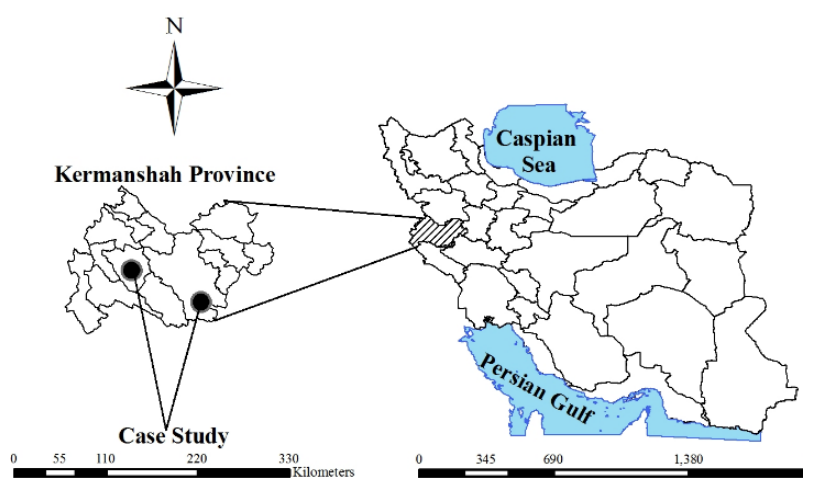

Figure 1. The locations of two selected sites

\subsection{Sampling Design and Field Measurements}

To ensure the proper distribution of plots in full range of forest coverage, first, we stratified the study areas into three stratums based on Landsat-derived leaf area index map using global model presented by Myneni et al. (1997) (see Nole et al., 2009). Totally, 124 reference plots with $30 \times 30$ meters dimensions (according to a Landsat pixel size) were systematically placed within two study sites in June and July 2015. To reduce the effect of the mismatch of spatial scale between the area encompassed by a measurement plot and the area of a remotely sensed pixel, the plots were selected based on the criterion that the surrounding forest vegetation within at least $10 \mathrm{~m}$ distance from the plot be the same as within the plot (Eckert, 2012; Eisfelder et al., 2011). The aboveground carbon of standing trees in inventoried plots was calculated using species-specific allometric functions (Iranmanesh, 2013).

\subsection{Remote Sensing Data and Processing}

The study forests are covered by one Landsat- 8 OLI image (path/row: 167/36). One cloud-free image acquired at 25 July 2015 was obtained from USGS Earth Resource Observation and Science Center archive (http://earthexplorer.usgs.gov). The Landsat-8 OLI image bands were converted from digital number format to reflectance, and then was atmospherically corrected using the MODTRAN based on the Fast Line-of-sight Atmospheric Analysis of Hypercube (FLAASH) radiative transfer algorithm (Matthew et al., 2000; Dube and Mutanga, $2015 b)$. The image was then geometrically controlled by digital maps that were produced by National Cartographic Center of Iran (http://www.ncc.org.ir/)

\subsection{Landsat-8 OLI Derived Textural Metrics}

The textural metrics were statistically calculated using Grey Level Co-occurance Matrix (GLCM) of Landsat-8 OLI bands. Many textural metrics can be derived from the GLCM; we used the nine metrics of mean, variance, homogeneity, contrast, dissimilarity, entropy, second moment, inverse difference and correlation (Wijaya et al., 2010; Eckert, 2012; Kelsey and Neff, 2014; Dube and Mutanga, 2015b). Texture algorithms calculate a relative displacement vector $(d, \theta)$, which explains the spatial distribution of the level pairs separated by $d$ in direction $\theta$. In addition to $d$ and $\theta$, texture metrics are also dependent on the window size used to calculate the GLCM. It is important to find the best window size to derive the textural metrics, because a window that is too small may identify variations in pixel brightness that are irrelevant to variation of the dependent variable, whereas a window that is too large may overlook important variations in pixel brightness (Nicol and Sarker, 2011; Kelsey and Neff, 2014). Here, we determined the optimal window size by the window size that had the strongest correlation between texture-predicted biomass and observed biomass. In order to determine the optimal window size for our study, all texture metrics were calculated on four Landsat bands (Bands 2 5) using four window sizes: $3 \times 3,5 \times 5,7 \times 7$, and $9 \times 9$ pixels. For each window size, texture was also calculated at four offsets, $(\theta)$, represented in Cartesian coordinates as $[0,1],[1,1],[1,0]$, and [11]. (Kelsey and Neff, 2014; Dube and Mutanga, 2015b).

We used stepwise linear regression to model the plot level carbon stock based on derived textural metrics. Linear regression based on ordinary least squares is one of the most frequently used statistical approaches to model the correspondence between spectral and field data ( $\mathrm{Lu}, 2006)$. Adjusted R-square and root mean square error (RMSE) were considered as fitting parameters of calculated models.

\section{RESULTS}

The results of regression analysis for modelling AGC based on derived Landsat 8 OLI textural metrics are presented in tables 1. Based on the results, for window size $3 \times 3$, the best textural metric was mean followed by entropy. Band 4 and 2 showed the highest correlation, while Band 5 showed no correlation with AGC. The best offset was $[1,1]$.

For window size $5 \times 5$, the best textural metric was mean followed by entropy and contrast. Using this window size for deriving textural metrics resulted a better fitting parameters as well as higher number of correlated metrics than $3 \times 3$ window size. Band 4 and offset $[1,-1]$ had the highest correlations.

For window size $7 \times 7$, the best textural metric was mean followed by entropy, contrast, and variance. Obviously, this window size had a better performance for deriving textural metrics in comparison to $3 \times 3$ and $5 \times 5$ window sizes. Offset $[1,-1]$ showed better fitting parameters. 
Table 1. AGBC estimates using Landsat 8 texture metrics from $3 \times 3,5 \times 5,7 \times 7,9 \times 9$ window sizes and offsets $[0,1],[1,0],[1,1]$, $[1,-1]$ using stepwise linear regression

\begin{tabular}{|c|c|c|c|c|}
\hline Offset & Image data & Variable name & $\mathrm{R}_{\text {adj }}^{2}$ & RMSE \\
\hline $3 \times 3$ & & & & \\
\hline \multirow[t]{4}{*}[0,1]{} & b2 & 8,5 & 0.43 & 333.7 \\
\hline & b3 & 8,5 & 0.42 & 335.0 \\
\hline & b4 & 8,1 & 0.45 & 328.1 \\
\hline & b5 & 8 & 0.03 & 433.6 \\
\hline \multirow[t]{4}{*}[1,1]{} & b2 & 8,7 & 0.45 & 328.2 \\
\hline & b3 & 8,5 & 0.43 & 334.2 \\
\hline & b4 & 8,1 & 0.45 & 326.4 \\
\hline & b5 & 8 & 0.03 & 433.9 \\
\hline \multirow[t]{4}{*}[1,-1]{} & b2 & $8,5,3$ & 0.41 & 338.5 \\
\hline & b3 & 8 & 0.38 & 348.6 \\
\hline & $\mathrm{b} 4$ & 8 & 0.38 & 348.6 \\
\hline & b5 & 8,13 & 0.06 & 427.1 \\
\hline \multirow[t]{4}{*}[1,0]{} & b2 & 8,5 & 0.42 & 337.3 \\
\hline & b3 & 8,5 & 0.43 & 334.2 \\
\hline & b4 & 8,1 & 0.45 & 326.4 \\
\hline & b5 & 8 & 0.03 & 433.9 \\
\hline \multicolumn{5}{|l|}{$5 \times 5$} \\
\hline \multirow[t]{4}{*}[0,1]{} & b2 & $8,2,4$ & 0.44 & 329.8 \\
\hline & b3 & $8,5,2,1$ & 0.48 & 318.2 \\
\hline & b4 & $8,1,2,4$ & 0.49 & 314.7 \\
\hline & b5 & - & - & - \\
\hline \multirow[t]{4}{*}[1,1]{} & $\mathrm{b} 2$ & $8,3,6,9$ & 0.43 & 331.8 \\
\hline & b3 & $6,8,2$ & 0.60 & 280.5 \\
\hline & $\mathrm{b} 4$ & $8,2,5$ & 0.48 & 318.7 \\
\hline & b5 & 3 & 0.08 & 422.7 \\
\hline \multirow[t]{4}{*}[1,-1]{} & $\mathrm{b} 2$ & $7,5,3,2$ & 0.46 & 335.6 \\
\hline & b3 & $8,5,3,2$ & 0.49 & 315.3 \\
\hline & b4 & $8,5,13$ & 0.50 & 313.4 \\
\hline & b5 & 4,9 & 0.14 & 409.3 \\
\hline \multirow[t]{4}{*}[1,0]{} & $\mathrm{b} 2$ & $8,5,9$ & 0.38 & 347.3 \\
\hline & b3 & 8,5 & 0.39 & 343.4 \\
\hline & b4 & 8,1 & 0.44 & 330.4 \\
\hline & b5 & - & - & - \\
\hline \multicolumn{5}{|l|}{$7 \times 7$} \\
\hline \multirow[t]{4}{*}[0,1]{} & b2 & $7,2,9$ & 0.44 & 329.3 \\
\hline & b3 & $8,5,2$ & 0.45 & 326.4 \\
\hline & b4 & $8,2,7$ & 0.51 & 310.2 \\
\hline & b5 & - & - & - \\
\hline \multirow[t]{4}{*}[1,1]{} & $\mathrm{b} 2$ & $8,5,4$ & 0.39 & 344.6 \\
\hline & b3 & $8,5,4$ & 0.44 & 330.9 \\
\hline & b4 & $8,2,5$ & 0.48 & 319.3 \\
\hline & b5 & 2,4 & 0.19 & 397.2 \\
\hline \multirow[t]{4}{*}[1,-1]{} & $\mathrm{b} 2$ & $8,3,5,2$ & 0.45 & 326.7 \\
\hline & b3 & $6,8,9$ & 0.46 & 322.9 \\
\hline & b4 & $8,1,9,7$ & 0.52 & 306.9 \\
\hline & b5 & $4,9,3$ & 0.22 & 388.4 \\
\hline \multirow[t]{4}{*}[1,0]{} & $\mathrm{b} 2$ & $8,5,9$ & 0.37 & 349.4 \\
\hline & b3 & $8,5,9$ & 0.42 & 334.3 \\
\hline & b4 & $8,1,9$ & 0.46 & 325.1 \\
\hline & b5 & - & - & - \\
\hline \multicolumn{5}{|l|}{$9 \times 9$} \\
\hline \multirow[t]{4}{*}[0,1]{} & b2 & $6,4,8$ & 0.48 & 319.0 \\
\hline & b3 & $5,8,9$ & 0.46 & 323.8 \\
\hline & b4 & $5,2,7$ & 0.54 & 298.1 \\
\hline & b5 & 2,4 & 0.22 & 388.9 \\
\hline$[1,1]$ & $\mathrm{b} 2$ & $8,5,4$ & 0.42 & 336.9 \\
\hline & b3 & $8,5,4$ & 0.46 & 324.3 \\
\hline & b4 & $5,9,8$ & 0.53 & 301.7 \\
\hline & b5 & $2,5,1$ & 0.25 & 381.1 \\
\hline$[1,-1]$ & $\mathrm{b} 2$ & $10,8,9$ & 0.45 & 327.1 \\
\hline
\end{tabular}

\begin{tabular}{rllll} 
& b3 & $5,8,9$ & 0.49 & 313.9 \\
b4 & $5,9,8$ & 0.53 & 301.7 \\
b5 & 6,1 & 0.22 & 390.8 \\
{$[1,0]$} & b2 & $5,8,9$ & 0.40 & 340.7 \\
b3 & $5,8,9$ & 0.44 & 329.6 \\
b4 & $5,8,9$ & 0.50 & 312.4 \\
b5 & 5, 2, 1, 4 & 0.24 & 385.9 \\
\hline 1=Ang2nd, 2=Contrast, 3=Correlation, & 4=Dissimilar, \\
5=Entropy, 6=Homogeneity, 7=Inverse Difference, 8=Mean, \\
9=variance, The best results are shown in bold.
\end{tabular}

For window size $9 \times 9$, the best textural metric was mean followed by entropy, contrast, and variance. This window size had a better performance for deriving textural indices in comparison to other window sizes. Offset $[1,-1]$ showed better fitting parameters. Overall, the best metric was mean followed by entropy, the bets band was 4 , the best offset was $[1,-1]$, and the best window size was $9 \times 9$.

\section{DISCUSSION}

RS based estimates have the potential to estimate the forest biomass or carbon over large areas with less efforts, time and cost than field based estimates. In this study we explored the ability of Landsat 8 OLI derived texture metrics for forest carbon estimation in two study site of coppice Oak forest.

Selecting suitable texture indices for biomass estimation is a challenging task. Because texture varies with the characteristics of the landscape and RS data used. Even for the same texture measure, selecting an appropriate window size and image band is crucial. Choosing a small window size for deriving texture may exaggerate the difference within the moving windows, while too large window sizes may not effectively extract information due to smoothing the texture variation.

We reached the best results by using mean index derived from band 4 using $9 \times 9$ window size and $[1,-1]$ offset. Overall, in our study the best model was able to explain about 50 percent of variation in the AGC. Du et al. (2010) used Landsat images and linear regression for modelling bamboo biomass and reported an $\mathrm{R}^{2}$ of 0.13. Gasparri et al. (2010) estimated the AGB and reported an $\mathrm{R}^{2}$ of 0.37 using Landsat data. Wijaya et al. (2010) reported a Pearson correlation of $0.544 \%$ for AGB estimation in Indonesia. Compared to our results, our study may have shown an improvement in the capabilities of Landsat images for AGC estimation. But our results are poor compare to Dube and Mutanga work (2015b). We examined the relationship between the AGC of coppice oak and texture metrics using a linear modelling method while they used nonlinear algorithms like stochastic gradient boosting. Du et al. (2010) claimed that the spectral responses of biophysical property are often nonlinear, so, some nonlinear methods such as Random Forest, support vector machine and etc. should be paid more attention in such contexts. In this study, half of the variation in AGC wasn't explained by textural metrics. This might be because of geometric misregistration between Landsat data and sample plots. Because of the size of Landsat pixels (30 meters), very precise geometric registration of images isn't possible.

On the other hand, selecting the optimal sample size is ambiguous. Smaller plot might result in saturation in dense leaf canopies, while larger sample size might smooth the variation of forest stands. Furthermore, there is a limitation for modelling a three-dimensions variable like biomass based on spectral reflectance, because optical sensors mainly capture canopy information and associated canopy shadows ( $\mathrm{Lu}$ and Batistella, 2005).

Although our results showed that using textural metrics for mapping biomass might be a proper solution, but caution needs 
to be taken when textures are used for estimating carbon stock in different sites because they are dependent on the structure of the forest stands and the image data.

\section{REFERENCES}

Behera, M.D., Tripathi, P., Mishra, B., Kumar, Sh., Chitale, V.S., Behera, S.K., 2016. Above-ground biomass and carbon estimates of Shorea robusta and Tectona grandis forests using QuadPOL ALOS PALSAR data. Advances in Space Research, 57, pp. 552 561.

Boudreau, J., Nelson, R.F., Margolis, H.A., Beaudoin, A., Guindon, L., Kimes, D.S., 2008. Regional aboveground forest biomass using airborne and spaceborne LiDAR in Que'bec. Remote Sensing of Environment, 112, pp. 3876-3890.

Chen, Y., Luo, G., Maisupova, B., Chen, X., Mukanov, B.M., Wu, M., Mambetov, B.T., Huang, J., Li, Ch., 2016. Carbon budget from forest land use and management in Central Asia during 1961-2010. Agricultural and Forest Meteorology, 221, pp. 131-141.

Cutler, M.E.J., Boyd, D.S., Foody, G.M., Vetrivel, A., 2012. Estimating tropical forest biomass with a combination of SAR image texture and Landsat TM data: An assessment of predictions between regions. ISPRS Journal of Photogrammetry and Remote Sensing, 70, pp. 66-77.

Du, H., Zhou, G., Ge, H., Fan, W., Xu, X., Fan, W., Shi, Y., 2012. Satellite-based carbon stock estimation for bamboo forest with a non-linearpartial least square regression technique. International Journal of Remote Sensing, 33(6), pp. 1917-1933.

Dube, T., Mutanga, O., 2015a. Quantifying the variability and allocation patterns of aboveground carbon stocks across plantation forest types, structural attributes and age in subtropical coastal region of KwaZulu Natal, South Africa using remote sensing. Applied Geography, 64, pp. 55-65.

Dube, T., Mutanga, O., 2015b. Investigating the robustness of the new Landsat- 8 Operational Land Imager derived texture metrics in estimating plantation forest aboveground biomass in resource constrained areas. ISPRS Journal of Photogrammetry and Remote Sensing, 108, pp. 12-32.

Eckert, S., 2012. Improved Forest Biomass and Carbon Estimations Using Texture Measures from WorldView-2 Satellite Data. Remote Sensing, 4, pp. 810-829.

Frazier, R.J., Coops, N.C., Wulder, M.A., Kennedy, R., 2014. Characterization of aboveground biomass in an unmanaged boreal forest using Landsat temporal segmentation metrics. ISPRS Journal of Photogrammetry and Remote Sensing, 92, pp. 137-146.

Garcia, M., Riano, D., Chivieco, E., Danson, F.M., 2010. Estimating biomass carbon stocks for a Mediterranean forest in central Spain using LiDAR height and intensity data. Remote Sensing of Environment, 114, pp. 816-830.

Gasparri, N.I., Parmuchi, M.G., Bono, J., Karszenbaum, H., Montenegro, C.L., 2010. Assessing multi-temporal Landsat 7 $\mathrm{ETM}+$ images for estimating above-ground biomass in subtropical dry forests of Argentina. Journal of Arid Environments, 74(10), pp. 1262-1270.

Kelsey, K.C., Neff, J.C., 2014. Estimates of Aboveground Biomass from Texture Analysis of Landsat Imagery. Remote Sensing, 6, pp. 6407-6422.

Krankina, O.N., Harmon, M.E., Cohen, W.B., Oetter, D.R., Zyrina, O., Duane, M.V., 2004. Carbon stores, sinks, and sources in forests of North- western Russia: Can we reconcile forest inventories with remote sensing results?. Climatic Change. 67, pp. 257-272.

Kwak, D.A., Lee, S.H., Kim, S.R., Lee, W.K., Son, Y., Cho, H.K., Kafatos, M., 2010. Estimating stem volume and biomass of Pinus koraiensis using LiDAR data. Journal of Plant Research, 123, pp. 421-432.

Langner, A., Samejima, H., Ong, R.C., Titin, J., Kitayama, K., 2012. Integration of carbon conservation into sustainable forest management using high resolution satellite imagery: A case study in Sabah, Malaysian Borneo. International Journal of Applied Earth Observation and Geoinformation, 18, pp. 305-312.

Lu, D., Batistella, M., 2005.Exploring TM image texture and its relationships with biomass estimation in Rondônia, Brazilian Amazon. Acta Amazonica, 35(2), pp. 261-268.

Lu, D., Chen, Q., Wang, G., Liu, L., Li, G., Moran, E., 2014. A survey of remote sensing-based aboveground biomass estimation methods in forest ecosystems. International Journal of Digital Earth, 27(7), pp. 1297-1328.

Lu, D.S., 2006. The potential and challenge of remote sensingbased biomass estimation. International Journal of Remote Sensing, 27, pp. 1297-328.

Muukkonena, P., Heiskanenb, L., 2007. Biomass estimation over a large area based on standwise forest inventory data and ASTER and MODIS satellite data: A possibility to verify carbon inventories. Remote Sensing of Environment, 107, pp. 617-624.

Neba, Sh.G., Kanninen, M., Atyi, R.E., Sonwa, D.J., 2014. Assessment and prediction of above-ground biomass in selectively logged forest concessions using field measurements and remote sensing data: Case study in South East Cameroon. Forest Ecology and Management, 329, pp. 177-185.

Nichol, J.E., Sarker, M.R., 2011. Improved biomass estimation using the texture parameters of two high-resolution optical sensors. IEEE Transactions and Geoscience and Remote Sensing, 49, pp. 930-948.

Patenaude, G. L., Milne, R., Dawson, T. P., 2005. Synthesis of remote sensing approaches for forest carbon estimation: Reporting to the Kyoto Protocol. Environmental Science \& Policy, 8, pp. 161-178.

Patenaude, G., Hill, R.A., Milne, R., Gaveau, D.L.A., Briggs, B.B.J., Dawson, T.P. 2004. Quantifying forest above ground carbon content using LiDAR remote sensing. Remote Sensing of Environment, 93, pp. 368-380.

Valipour, A., Plieninger, T., Shakeri, T., Ghazanfari, H., Namiranian, M., Lexer, M.J., 2014. Traditional silvopastoral management and its effects on forest stand structure in northern Zagros, Iran. Forest Ecology and Management. 327, pp. 221-230. Wen, D., He, N., 2016. Forest carbon storage along the northsouth transect of eastern China: Spatial patterns, allocation, and influencing factors. Ecological Indicators, 61, pp. 960-967.

Wijaya, A., Kusnadi, S., Gloaguen, R., Heilmeier, H., 2010. Improved strategy for estimating stem volume and forest biomass using moderate resolution remote sensing data and GIS. Journal of Forestry Research, 21(1), pp. 1-12.

Zhao, K., Popescu, S., Nelson, R., 2009. Lidar remote sensing of forest biomass: a scale-invariant estimation approach using airborne lasers. Remote Sensing of Environment, 113(1), pp. 182196. 